\title{
Treatment with Interferon- $\alpha$ Preferentially Reduces the Capacity for Amplification of Granulocyte-Macrophage Progenitors (CFU-GM) from Patients with Chronic Myeloid Leukemia but Spares Normal CFU-GM
}

\author{
M.Y. Gordon, S.B. Marley, J.L. Lewis, R.J. Davidson, D.X. Nguyen, F.H. Grand, T.A.S. Amos, and J.M. Goldman \\ Department of Haematology, Imperial College School of Medicine, Hammersmith Hospital, London W12 ONN, United Kingdom
}

\begin{abstract}
The biological target for interferon (IFN)- $\alpha$ in chronic myeloid leukemia (CML) is unknown, but one possibility is that amplification of granulocyte-macrophage colony-forming cells (CFU-GM) is reduced. Replating CFU-GM colonies and observing secondary colony formation provides a measure of CFU-GM amplification. Amplification of CML, but not normal, CFU-GM in vitro was significantly inhibited by IFN- $\alpha(P=0.02)$. In 5 out of 15 CML cases studied by fluorescence in situ hybridization, in vitro treatment with IFN- $\alpha$ increased the proportion of CFU-GM, which lacked BCRABL. The ability of patients' CFU-GM to amplify, and suppression of this ability by IFN- $\alpha$, predicted responsiveness to IFN- $\alpha$ therapy in $86 \%$ of cases. Investigation of patients on treatment with IFN- $\alpha$ showed a threefold reduction in CFU-GM amplification in responders $(P=0.03)$ but no significant change in nonresponders $(P=0.8)$. We conclude that IFN- $\alpha$ preferentially suppresses amplification of CML CFU-GM to varying degrees. The differing in vitro sensitivities to IFN- $\alpha$ and growth kinetics of individual patients' cells could help differentiate those who will or will not benefit from treatment with IFN- $\alpha$. (J. Clin. Invest. 1998. 102: 710-715.) Key words: BCR-ABL • fluorescence in situ hybridization • therapy $\bullet$ prognosis $\bullet$ expansion
\end{abstract}

\section{Introduction}

Chronic myeloid leukemia (CML) $)^{1}$ is a malignant myeloproliferative disease characterized by well-differentiated myeloid hyperplasia during its chronic phase (1). This is presumed to be a result of changes induced by the expression of the p210

The work was supported by the Leukaemia Research Fund of Great Britain and Leuka 2000.

T.A.S. Amos's present address is Department of Haematology, Royal United Hospital, Bath BA1 3NG, UK.

Address correspondence to Professor M.Y. Gordon, Department of Haematology, Hammersmith Hospital, Imperial College School of Medicine, DuCane Road, London W12 ONN, United Kingdom. Phone: 44-181-383-3430; FAX: 44-181-740-9679; E-mail: mgordon@ rpms.ac.uk

Received for publication 10 February 1998 and accepted in revised form 29 May 1998.

1. Abbreviations used in this paper: AUC, areas under the curve; CFU-GM, granulocyte-macrophage colony-forming cells; CML, chronic myeloid leukemia; Ph, Philadelphia.

J. Clin. Invest.

(C) The American Society for Clinical Investigation, Inc. 0021-9738/98/08/0710/06 \$2.00

Volume 102, Number 4, August 1998, 710-715

http://www.jci.org protein tyrosine kinase product of the $\mathrm{BCR}-\mathrm{ABL}$ fusion gene formed by the Philadelphia $(\mathrm{Ph})$ chromosomal translocation between chromosomes 9 and 22. In spite of detailed molecular knowledge, little is known about the precise biological defect that results in myeloid hyperplasia in CML. The leukemic cell expansion in CML must in some way result from perturbed cell proliferation, cell amplification and/or cell death (apoptosis) during hematopoietic cell development. Reduced apoptosis has been postulated as an explanation for the myeloid expansion, but we and others (2-6) have not been able to confirm the notion $(7,8)$ that it is an important mechanism in the pathogenesis of CML.

Interferon (IFN)- $\alpha$ has been used to treat CML patients with beneficial results. In particular, the emergence of $\mathrm{Ph}$-negative, presumably normal, hematopoiesis in a significant proportion of CML patients treated with IFN- $\alpha$ indicates a differential effect on normal and malignant hematopoietic precursor cells (9). However, the mechanism of this effect is not known. There is no substantial difference in the sensitivity of primary normal and CML clonogenic progenitor cells (granulocyte-macrophage colony-forming cells [CFU-GM] and erythroid burst-forming units [BFU-E]) to treatment with IFN- $\alpha$ in vitro (10-12). An alternative explanation has been sought by postulating that the defective adhesion to bone marrow stromal cells that characterizes primitive hematopoietic progenitor cells in CML (13-15) is reversed by IFN- $\alpha$ therapy, so that malignant progenitor cell proliferation can be controlled by inducing them to interact with the bone marrow microenvironment $(16,17)$. However, whereas improved adhesion by CML cells can be demonstrated in the presence of IFN- $\alpha$ in vitro, some studies have shown that this is the result of an indirect effect of IFN- $\alpha$ on stromal cells rather than on the malignant progenitor cells themselves (16).

We reasoned that identification of the kinetic difference between normal and leukemic hematopoietic progenitor cells that explained myeloid hyperplasia in CML might reveal the therapeutic target of IFN- $\alpha$ and potentially of other therapeutic modalities. Here we have shown that amplification in cell number within the CFU-GM compartment in vivo is highly likely to contribute to myeloid expansion in CML, and we have tested the hypothesis that CFU-GM amplification is targeted by treatment with IFN- $\alpha$. We have demonstrated that CFU-GM amplification is suppressed in vivo in patients being treated with IFN- $\alpha$ and that the abilities of CML and normal CFU-GM to amplify in vitro are differentially sensitive to exposure to IFN- $\alpha$. Moreover, we have demonstrated that these in vitro measurements potentially provide the basis for a prognostic test for IFN- $\alpha$ responsiveness in individual CML patients at the time of diagnosis.

\section{Methods}

Patients and samples

All samples were obtained with informed consent and research ethics committee approval. Peripheral blood samples were obtained from 
patients with chronic phase CML when they visited the outpatient clinic at the Hammersmith Hospital. IFN-treated patients were given 3-9 MU/d, 5 d per week for at least $6 \mathrm{mo}$. In some cases, cells that had been cryopreserved at the time of diagnosis were thawed rapidly and diluted in HBSS containing 10\% FCS and $10 \mathrm{U} / \mathrm{ml}$ DNAse II before use. Normal bone marrow cells were obtained from donations for allogeneic transplantation. Normal blood cells were obtained from normal volunteers.

\section{Cell culture}

Pre-CFU-GM progenitor cell assay. Primitive pre-CFU-GM progenitor cells were assayed as previously described $(18,19)$. The assay detects the activity of CD34-positive cells that are predominantly CD33, CD38, and HLA-DR negative and are capable of producing erythroid BFU-E as well as CFU-GM $(19,20)$. In brief, the mononuclear cell fraction was separated from the blood and bone marrow samples by using Lymphoprep (Nycomed, Oslo, Norway), washed three times, and resuspended in alpha medium (GIBCO, Paisley, UK) supplemented with $15 \%$ FCS. Then mononuclear cells were resuspended at a concentration of $10^{6} \mathrm{cells} / \mathrm{ml}$ in alpha medium supplemented with $15 \%$ FCS. $10 \mathrm{ml}$ of cell suspension were placed in $25-\mathrm{cm}^{2}$ tissue culture flasks and incubated for $2 \mathrm{~h}$ at $37^{\circ} \mathrm{C}$ in humidified $5 \% \mathrm{CO}_{2}$ in air. The plastic nonadherent cells were removed by thorough washing in three changes of HBSS. Finally, alpha medium containing $2 \times 10^{-6} \mathrm{M}$ methylprednisolone (Upjohn, Crawley, UK), 10\% horse serum, 10\% FCS, 10\% 5637 conditioned medium, and graded concentrations of IFN- $\alpha$ was added to the plastic adherent cells, and they were incubated for $7 \mathrm{~d}$ at $37^{\circ} \mathrm{C}$ in humidified $5 \% \mathrm{CO}_{2}$ in air. The nonadherent progeny of the adherent cells were then harvested and transferred to the CFU-GM assay (see below). For some experiments, the cultures were prolonged by weekly feeding, as described earlier (21), and CFU-GM production was measured at weekly intervals.

$C F U-G M$ assay and replating. Mononuclear cells were depleted of plastic-adherent cells by incubation in tissue culture plastic flasks for $2 \mathrm{~h}$ at $37^{\circ} \mathrm{C}$ in humidified $5 \% \mathrm{CO}_{2}$ in air. Nonadherent bone marrow or blood mononuclear cells were plated at a concentration of $10^{5}$ cells/ml in methylcellulose containing serum (Methocult H4230; Metachem Diagnostics Ltd, Northampton, UK) and supplemented with recombinant human cytokines $(1 \mathrm{ng} / \mathrm{ml}$ GM-CSF, $100 \mathrm{ng} / \mathrm{ml}$ G-CSF, $5 \mathrm{ng} / \mathrm{ml} \mathrm{IL-3,} 20 \mathrm{ng} / \mathrm{ml}$ stem cell factor, all from First Link, West Midlands, UK) in petri dishes. The cultures were incubated at $37^{\circ} \mathrm{C}$ in humidified $5 \% \mathrm{CO}_{2}$ in air for $7 \mathrm{~d}$, and then colonies consisting of at least 50 cells were scored.

In some experiments CFU-GM were grown in the presence of 0 , 50,100 , and $500 \mathrm{U} / \mathrm{ml} \mathrm{IFN-} \alpha$ (Roche Products, Welwyn Garden City, UK). Then, for each experimental group, 120 sequential colonies consisting of more than 50 cells were plucked individually from the methylcellulose by using an Eppendorf pipette. Preliminary experiments had shown that replating ability peaks $5-7 \mathrm{~d}$ after initiation of the primary culture; for convenience, replating was performed on day 7 . The number 120 CFU-GM for replating was chosen because it is the maximum that is practicable on a regular basis (especially where more than one experimental group is involved at a time) and because the data are ultimately expressed in the form of a distribution (see below). Smaller numbers are not likely to reveal the true extent of this distribution (22). Each colony was transferred to a separate well of a 96-well microtitre plate containing $100 \mu \mathrm{l}$ of methylcellulose plus serum and cytokines. The colonies were dispersed to a single-cell suspension and thoroughly mixed with the methylcellulose. Then the microtitre plates were incubated for a further $7 \mathrm{~d}$ at $37^{\circ} \mathrm{C}$ in humidified $5 \% \mathrm{CO}_{2}$ in air. Each well was scored for the presence and number of secondary CFU-GM consisting of more than 50 cells.

The data were analyzed using a Microsoft Excel spreadsheet version 5.0 (Microsoft Corporation, Redmond, WA) on a Macintosh computer. The raw data are the number of primary CFU-GM producing secondary CFU-GM. The numbers of secondary CFU-GM $(n)$ produced by individual primary CFU-GM range from zero to the maximum observed. A cumulative distribution is then obtained for the proportion of primary CFU-GM producing more than $n$ secondary CFU-GM. This proportion is plotted on a logarithmic scale (yaxis) so that changes by the same proportion are given the same magnitude on the graph. The $\mathrm{x}$-axis ( $n$ is the number of secondary colony-forming cells per primary colony-forming cell) is plotted as $\log _{2} n$ because the number of secondary colony-forming cells increases as the square of the number of self-replicating divisions that the cells in the primary CFU-GM colony have passed through. Finally, areas under the curves (AUCs) are calculated using the Trapezium Rule (23). We considered the AUC to be the most appropriate way to express the data for several reasons. First, the productive capacity of the replated population will be the product of the percentage of colonies with replating activity and the number of secondary colonies produced; second, the AUC takes account of the proportion of CFU-GM that do not produce any secondary colonies on replating; third, the distribution of the number of secondary colonies produced by individual primary normal marrow colonies is highly skewed (corrected coefficient of skewness $=6.9 \pm 2.5[$ mean $\pm \mathrm{SD}]$; range $=3.4$ 12.4 ; values $>2$ are highly significant; 24 ).

\section{Statistical analysis}

Student's $t$ test (unpaired; two tailed) and nonparametric statistical analysis (Mann-Whitney U test) were performed using StatView SE + Graphics software for the Macintosh computer (Abacus Concepts Inc., Berkeley, CA). AUCs were calculated using an Excel5 spreadsheet on a Macintosh computer.

\section{Fluorescence in situ hybridization}

Individual primary colonies were plucked from methylcellulose culture, fixed in $15 \mu \mathrm{l}$ methanol/acetic acid for $5 \mathrm{~min}$ and then transferred to multicompartmentalized microscope slides and dried by evaporation. Secondary CFU-GM colonies from individual wells were pooled and then treated in the same way. Because the cells in the primary colonies and in the secondary colonies are derived from a single colony-forming cell, all of them will be BCR-ABL positive or negative.

The slides were dehydrated in ascending concentrations of alcohol, denatured, and dehydrated again. The cells were then probed using a mixture of BCR sequences labeled with SpectrumGreen and ABL sequences labeled with SpectrumOrange (Vysis, Woodcreek, IL). The probe mixture was denatured at $73^{\circ} \mathrm{C}$ for $5 \mathrm{~min}$ and immediately placed on the slides on a slide warmer at $45-50^{\circ} \mathrm{C}$. The slides were sealed with coverslips and incubated for $12 \mathrm{~h}$ at $37^{\circ} \mathrm{C}$ in a humidified atmosphere. Coverslips were then removed, and the slides were washed twice in $2 \times \mathrm{SSC}$, thrice in $50 \%$ formamide $/ 2 \times \mathrm{SSC} \mathrm{pH} 7.0-$ 7.2 , once in PBS, stained with DAPI, and mounted using Vectashield (Vector Laboratories Inc., Burlingame, CA). BCR-ABL-positive cells were identified by the coincidence of the green and orange signals (20).

\section{Results}

Production of CFU-GM by primitive progenitor cells is relatively insensitive to IFN- $\alpha$ in vitro. Since CML is a hematopoietic stem cell malignancy, it was important to evaluate the effect of IFN- $\alpha$ on primitive normal and CML cell populations. For this we used the production of CFU-GM by pre-CFU-GM progenitor cells as an endpoint. These pre-CFU-GM cells have been characterized as CD34 positive, CD33 negative, CD38 negative, HLA-DR negative and have the capacity to generate erythroid BFU-E as well as CFU-GM $(19,20)$. The data in Fig. 1 show that inclusion of IFN- $\alpha$ during the incubation period of the assay resulted in dose-dependent suppression of CFU-GM production, but there was no significant difference between the effects on normal and CML cells $(P>$ 0.05 at all doses; Mann-Whitney U test). Also, significant suppression was achieved only at doses $>500 \mathrm{U} / \mathrm{ml}$. 


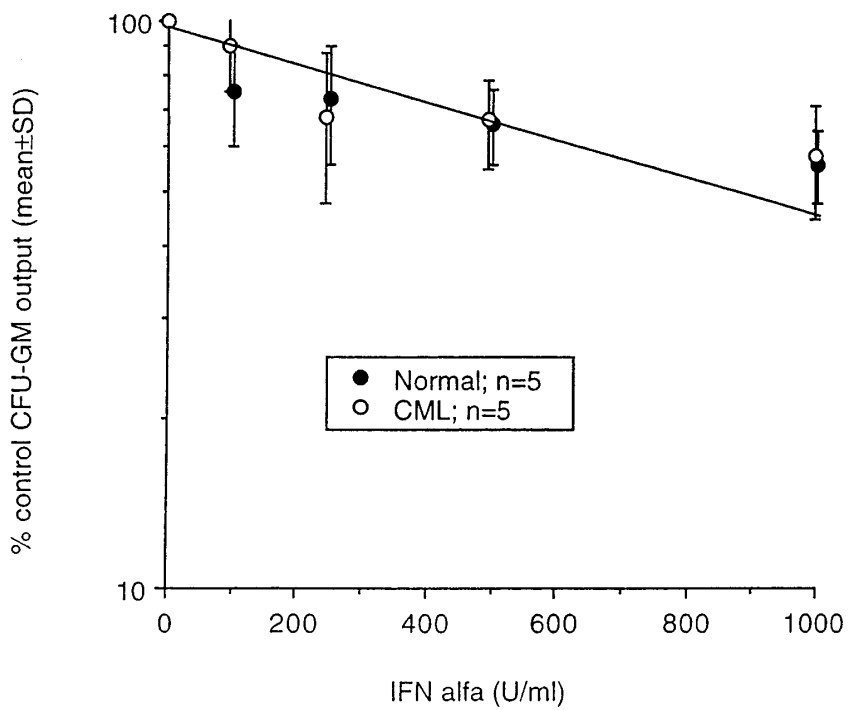

Figure 1. Dose-response relationship between the concentration of IFN- $\alpha$ and the suppression of CFU-GM production in the Pre-CFU$\mathrm{GM}$ assay. The symbols and vertical lines are the means $\pm \mathrm{SD}$, respectively. The control $(100 \%)$ values were $1476 \pm 427$ for normal CFUGM production and $1636 \pm 646$ for CML CFU-GM production.

We were not able to investigate the effects of IFN- $-\alpha$ after longer periods of time in culture because of the rapid disappearance of CML pre-CFU-GM from the system $(1.3 \pm 0.9$ $[n=4]$ of week 1 levels at week 2 , zero at week 3$)$. This is reminiscent of the performance of CML cells in long-term bone marrow cultures (unpublished data), as originally reported by Udomsakdi et al. (25).

Overall, these results suggest that primitive progenitor cells in CML may not be the only target for IFN- $\alpha$ therapy.

$C F U-G M$ amplification can be detected by replating $C F U$ $G M$ in vitro. It is well known that CFU-GM numbers are greatly increased in CML, whereas relative increases in more primitive hematopoietic cells appear to be much less marked $(25,26)$. These different degrees of amplification may imply that cell expansion occurs in CML in hematopoietic progenitor cell populations and might be at least partly responsible for expansion of the myeloid mass in CML.

Replating CFU-GM-derived colonies into secondary cultures and observing the formation of colonies by the replated cells provide a measure of the numbers of new colony-forming cells produced within the developing clone. In other words, it provides a measure of colony-forming cell amplification. To test whether differences in the capacity of normal and CML CFU-GM to amplify could be detected in vitro, CFU-GMderived colonies, grown from normal or CML hematopoietic cells, were individually replated into secondary cultures in the wells of microtitre plates. The data were expressed as the AUC (see Methods). The AUC for CML CFU-GM was $81 \pm 50$ (mean $\pm \mathrm{SD} ; n=28$ ); for normal bone marrow $70 \pm 42$ $(n=26)$, and for normal peripheral blood $42 \pm 28(n=25)$. The results for CML were significantly different from those for normal blood ( $P=0.0014$; Student's $t$ test) but not significantly different from normal bone marrow.

Interferon- $\alpha$ reduces amplification in CML CFU-GM in vitro and spares normal CFU-GM. When cells were cultured

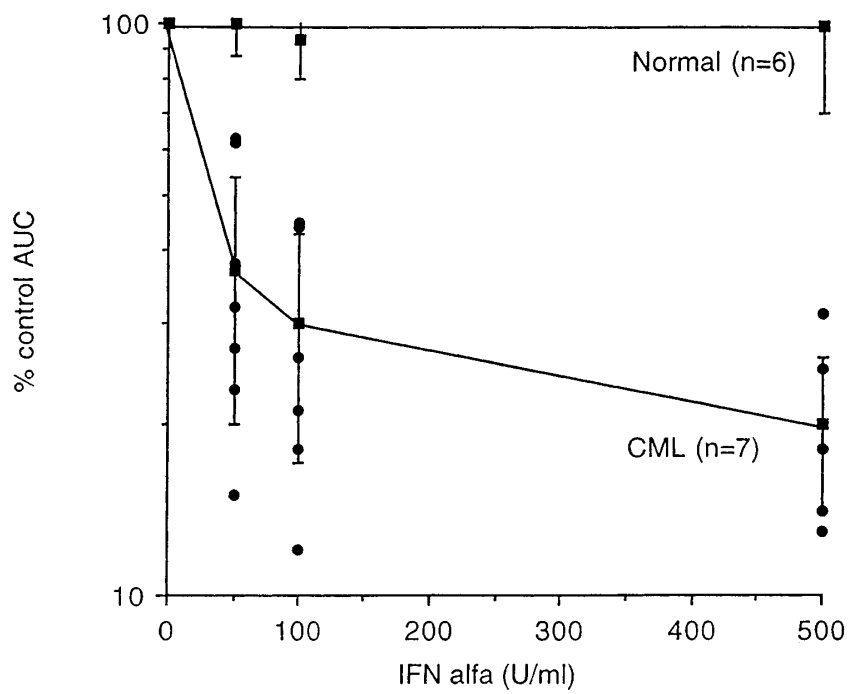

Figure 2. Dose-response relationship between the concentration of IFN- $\alpha$ and the AUC measured in secondary replating assays of CFUGM grown from normal marrow or CML blood. Primary CFU-GM were cultured in the presence of 0 to $500 \mathrm{U} / \mathrm{ml} \mathrm{IFN}-\alpha$, then replated into standard culture conditions (without IFN- $\alpha$ ) for secondary colony formation. Results are expressed as the AUC measured for IFN- $\alpha$-exposed groups relative to controls without IFN- $\alpha$ in the primary cultures. The squares and vertical lines are the experimental means $\pm \mathrm{SD}$, respectively. The circles indicate the results from the individual CML patients.

in concentrations of IFN- $\alpha$ up to $500 \mathrm{U} / \mathrm{ml}$, the numbers of primary CFU-GM were not significantly reduced, compared with numbers in control plates containing no IFN- $\alpha(P=0.14$ at $500 \mathrm{U}$ IFN- $\alpha / \mathrm{ml}$, Mann-Whitney U test; data not shown). Also,

Table I. Fluorescence In Situ Hybridization Analysis of Secondary CFU-GM Grown from Primary CML Blood CFU-GM Cultures in the Presence and Absence of IFN- $\alpha$

\begin{tabular}{lll}
\hline Patient No.* & Control & $+\operatorname{IFN}-\alpha(\%)$ \\
\hline 1 & $0 / 10$ & $3 / 11^{\ddagger}(27)^{\S}$ \\
2 & $0 / 10$ & $0 / 18$ \\
3 & $0 / 20$ & $0 / 6$ \\
4 & $0 / 12$ & $8 / 32(25)$ \\
5 & $0 / 18$ & $0 / 24$ \\
6 & $5 / 30(17)$ & $13 / 33(39)$ \\
7 & $0 / 21$ & $0 / 39$ \\
8 & $1 / 35(3)$ & $0 / 27$ \\
9 & $10 / 33(33)$ & $6 / 18(33)$ \\
10 & $0 / 20$ & $0 / 24$ \\
11 & $39 / 43(91)$ & $39 / 41(95)$ \\
12 & $0 / 8$ & $0 / 10$ \\
13 & $0 / 21$ & $0 / 39$ \\
14 & $0 / 27$ & $1 / 35(3)$ \\
15 & $0 / 10$ & $3 / 8(38)$ \\
\end{tabular}

*The patients investigated were six of the cases contributing to the data in Fig. 2 plus nine further cases who were studied using a single dose of $100 \mathrm{U} / \mathrm{ml} \mathrm{IFN}-\alpha$ in the primary CFU-GM cultures. ${ }^{*} \mathrm{BCR}-\mathrm{ABL}-$ negative colonies out of total colonies analyzed. ${ }^{\$}$ Percentage BCR-ABLnegative colonies. 
in common with other studies (10-12), we found that IFN- $\alpha$ does not have any differential effect on the growth of primary CFU-GM colonies. In contrast, when primary CML colonies, grown in the presence of IFN- $\alpha$, were replated there was a significant reduction in the AUCs. This reduction in AUC was not found for normal CFU-GM (Fig. 1; $P=0.02$ ). This result supports the idea that at least part of the beneficial effect of IFN- $\alpha$ therapy in CML patients results from a preferential reduction in the ability of the leukemic progenitors to expand in number.

One of the most important benefits of IFN- $\alpha$ therapy is that it allows the emergence of a Ph-negative hematopoiesis in a significant proportion of CML patients $(9,27)$. One mechanism for this might be provided by the differential effects on normal and CML progenitor cells as revealed by measurements of the AUCs obtained from IFN- $\alpha$-treated cells in vitro (Fig. 2). To investigate this aspect further, we used fluorescence in situ hybridization to investigate the BCR-ABL status of secondary colonies produced by primary CFU-GM grown in the presence of IFN- $\alpha$ before they were replated. No BCRABL-negative replated colonies were found in 11 of 15 control groups of colonies, grown in primary culture without IFN- $\alpha$ (Table I). Increased proportions of BCR-ABL-negative replated colonies were found in IFN-treated cultures from 5 of 15 patients, and no change in percentage of BCR-ABL-negative colonies in a further two.

The AUC and in vitro response to IFN- $\alpha$ may predict clinical responsiveness to IFN- $\alpha$ therapy. We identified seven patients who had complete cytogenetic responses to IFN- $\alpha$, and seven patients who did not respond cytogenetically. Cells from these patients had been cryopreserved at diagnosis and were available for study. The corresponding AUC values and effect of exposure to IFN- $\alpha$ are shown in Fig. $3 A$ and $B$. The AUC and its suppression by IFN- $\alpha$ were significantly different between the two groups of patients $(P=0.001$ and 0.03 , respectively). Although there was some overlap in the data sets, it is clear that patients who become cytogenetic responders on IFN- $\alpha$ therapy are characterized by a greater AUC and greater sensitivity to IFN- $\alpha$ in vitro when compared with nonresponders.

To determine whether the AUC and in vitro sensitivity combined could be used to identify IFN- $\alpha$ responders and nonresponders prospectively, we plotted the means \pm 2 standard deviations for the two groups as shown in Fig. $4 A$. The boxes in Fig. $4 B$ and $C$ mark the boundaries of two standard deviations from the mean values for the IFN- $\alpha$ responders and nonresponders, respectively. As seen in Fig. $4 B$, the data "gate" for responsive patients contained the data points from all responders and one nonresponder; similarly the gate for nonresponders contained the data from all nonresponders and one responder (Fig. $4 C$ ). Thus, overall the potential IFN- $\alpha$ responsiveness was wrongly identified in 2 out of 14 cases, giving an accuracy of $86 \%$.

IFN- $\alpha$ therapy reduces the AUC of CML patients CFU-GM in vivo. The AUC values for 19 patients who were being treated with IFN- $\alpha$ at the time of sampling were $32 \pm 30$ (mean $\pm \mathrm{SD})$. This is significantly lower $(P=0.004)$ than the value of $81 \pm 50$ for non-IFN- $\alpha$-treated patients (see above). Within this group, the AUC values for responders was $54 \pm 29$ $(n=5)$ and for nonresponders was $25 \pm 19(n=5 ; P=0.05)$. Comparing these values with the data in Fig. $3 A$ where the mean AUC at diagnosis was 157 for responders and 31 for

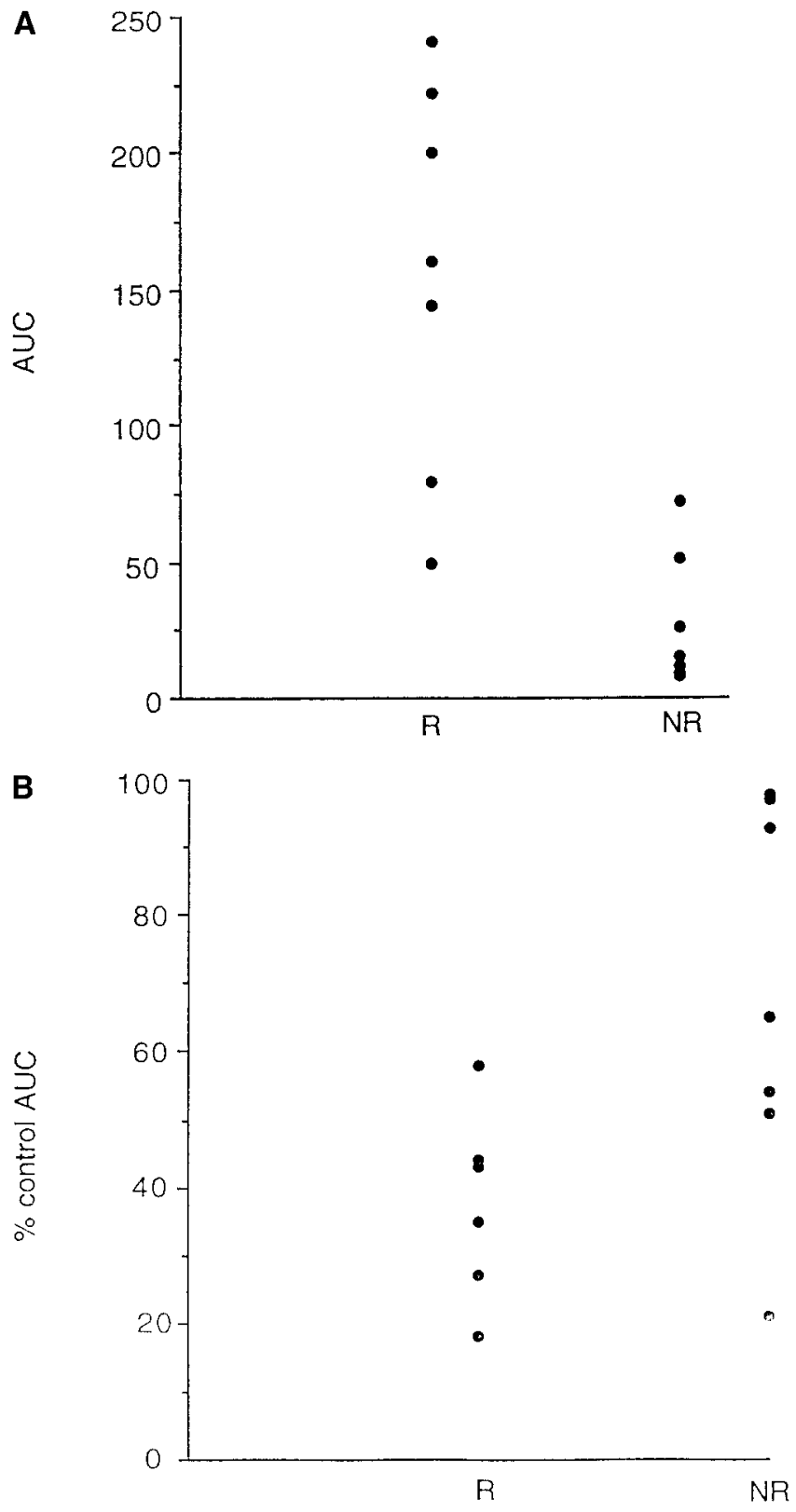

Figure 3. (A) AUC and (B) percentage of control AUC for cells cultured in the presence of $100 \mathrm{U} / \mathrm{ml}$ obtained for cells cryopreserved at presentation of patients who later became cytogenetic responders $(R)$ or nonresponders $(N R)$ to IFN- $\alpha$ therapy. Each data point represents the result from an individual patient.

nonresponders, this result indicates a threefold reduction $(P=$ $0.03)$ in AUC in vivo for responding patients and no significant change $(P=0.8)$ for nonresponding patients.

Sensitivity to $I F N-\alpha$ is retained during IFN- $\alpha$ therapy. We measured the reduction in AUC caused by exposure to 100 $\mathrm{U} / \mathrm{ml}$ IFN- $\alpha$ in vitro for six patients while they were being treated with IFN- $\alpha$. No attempt was made to divide this group into responders and nonresponders. The residual AUC was $45 \pm 25 \%$ of the control values, which is not significantly different $(P=0.7)$ from the mean sensitivity $(53 \pm 26 \%$ of controls $)$ of responders and nonresponders at diagnosis combined (see Fig. $3 \mathrm{~B}$ ) and does not deviate significantly from the range of 

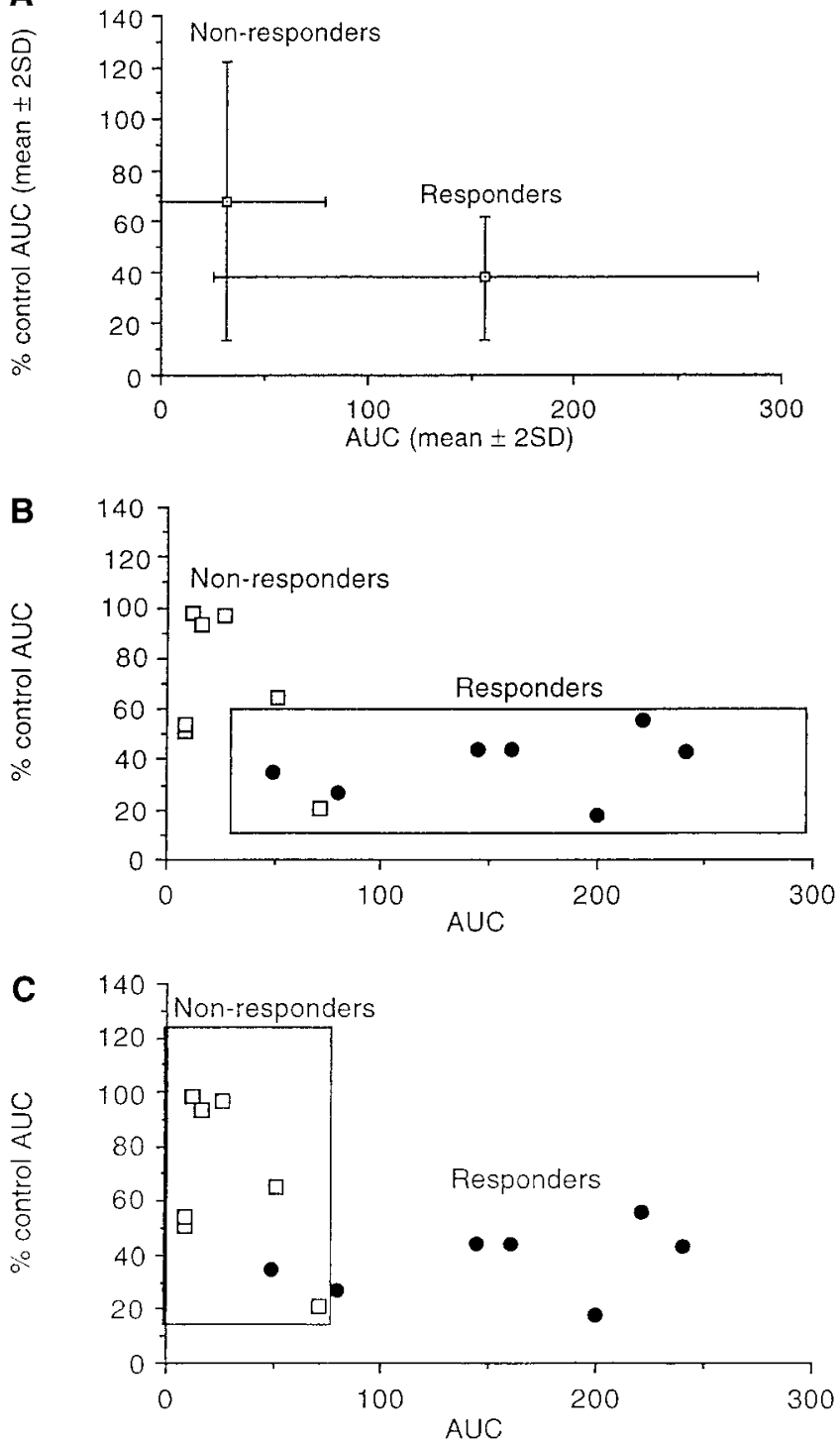

Figure 4. (A) The mean AUC \pm 2 (SD) of the data shown in Fig. $2 \mathrm{~A}$ for IFN- $\alpha$ responders and nonresponders is plotted on the $\mathrm{x}$-axis, and the mean percentage of control AUC in the presence of IFN- $\alpha$ (from Fig. $2 B$ ) is plotted on the y-axis. $(B)$ The AUC and percentage of control AUC in the presence of IFN- $\alpha$ for responders (circles) and nonresponders (squares). The data gate encloses the area defined by the two standard deviations for responders shown in Fig. $3 A$. $(C)$ Same as for Fig. $3 B$ except that the data gate encloses the area defined by the two standard deviations for nonresponders shown in Fig. 3 A.

values shown in Fig. 2. Thus, responsiveness to IFN- $\alpha$ may not be greatly altered during IFN- $\alpha$ therapy, at least in some patients.

\section{Discussion}

In CML, there must be a link between the deranged biological mechanism responsible for generating the myeloid hyperplasia and therapeutic responses reducing the myeloid cell mass. Identification of this link would be valuable for explaining the success of therapies such as IFN- $\alpha$ and in evaluating new ther- apeutic strategies. To achieve this goal, it is necessary to devise in vitro tests that model therapy-induced changes in leukemic cells in vivo.

Since CML is a stem cell disorder, it was important to investigate the effect of IFN- $\alpha$ on primitive hematopoietic cells. We used an assay that detects the activity of primitive preCFU-GM progenitor cells for this purpose. This assay detects CD34-positive precursors of CFU-GM that are predominantly negative for expression of the HLA-DR, CD33, and CD38 antigens (20). As well as CFU-GM, their progeny include erythroid BFU-E, cobblestone-area-forming cells and cells capable of sustaining hematopoiesis for $5 \mathrm{wk}$ in long-term cultures (19). The presence of IFN- $\alpha$ at physiological/pharmacological concentrations (28-31) did not significantly reduce the production of CFU-GM by normal or by CML pre-CFU-GM. Neither was there any differential effect in normal or CML cell cultures.

The lack of an effect of IFN- $\alpha$ on pre-CFU-GM cells might imply that does not act on malignant stem cells in CML. However, it is possible that IFN- $\alpha$ has an indirect effect on the CML stem cell population since suppressing leukemic CFUGM proliferation could result in the preferential recruitment of CML stem cells leading to progressive depletion of the malignant stem cell population. This hypothesis finds some support in the observation that the majority of primitive progenitor cells in CML are actively cycling while their normal counterparts are quiescent (32). It is also consistent with the fact that cytogenetic responses to IFN- $\alpha$ therapy in CML can take a considerable length of time to emerge (27).

To test this hypothesis, we used a colony replating assay as an in vitro model of the capacity of cells in the CFU-GM compartment to undergo amplification. The AUC measurement that we have devised relates to amplification by the whole CFU-GM population (see Methods) and was significantly suppressed in CML cell cultures but not in normal cell cultures. It is relevant that IFN- $\alpha$ was effective at concentrations corresponding to plasma levels, which occur physiologically or can be induced pharmacologically (28-31). Therefore, this result provides the first demonstration of a differential effect of IFN- $\alpha$ in vitro at concentrations that may be expected to occur in vivo.

In one-third of patients, the CFU-GM that produced secondary CFU-GM after exposure to IFN- $\alpha$ in vitro were found to include a higher proportion of BCR-ABL-negative (i.e., normal) cells than unexposed controls. Again, this supports the existence of a differential effect of IFN- $\alpha$ on normal and CML progenitor cells. The failure to detect BCR-ABL-negative surviving CFU-GM in the remaining patients may be a consequence of the relative sizes of the BCR-ABL-positive and -negative cell populations in CML, because it is known that BCR-ABL-negative cells constitute a very small proportion of the blood and bone marrow cells in CML patients (20).

When we investigated cells that had been cryopreserved at diagnosis from patients who had responded or had not responded cytogenetically to IFN- $\alpha$ therapy, we found clear differences between the two groups. The in vitro sensitivity to IFN- $\alpha$ of cells from patients who later responded to IFN- $\alpha$ was greater than the sensitivity of cells from nonresponders. More surprisingly, the AUC for responders was greater than that for nonresponders. One possible explanation for this paradoxical finding may be that a large AUC presents a large target for therapeutic attack; another might be that the replating test dis- 
criminates between two biological subgroups of patients that respond differently to IFN- $\alpha$ for unknown reasons. Taken together, these differences formed the basis of a potentially prognostic test, which may prove to be valuable in selecting patients for IFN- $\alpha$ therapy. This would have the advantage of reducing the toxicity and cost incurred by treating patients with little likelihood of responding to the treatment. Moreover, it would contribute towards accelerating the development of new therapeutic strategies for treating IFN- $\alpha$ nonresponsive disease.

In accord with the in vitro effects of IFN- $\alpha$ (Fig. 2), the AUC measured in responding patients while they were being treated with IFN- $\alpha$ was significantly reduced compared with that from responding patients at diagnosis. However, there was no significant reduction in nonresponding patients between the time of diagnosis and when they were being treated with IFN- $\alpha$. This result indicates that the in vitro action of IFN- $\alpha$ is reproduced in vivo and corresponds to the clinical IFN- $\alpha$ response status. Furthermore, the AUC in these patients was lower than the AUC for normal cells, indicating that normal cells might have a proliferative advantage in this setting. Finally, cells from IFN- $\alpha$-treated patients remained responsive to IFN- $\alpha$ in vitro. We did not have the opportunity to investigate patients who had become resistant to IFN- $\alpha$ in this study.

In summary, our data have identified a potential mechanism of action for IFN- $\alpha$ therapy of CML, which can be demonstrated in vitro and in vivo in IFN- $\alpha$-treated patients. These IFN- $\alpha$-induced changes may provide a prognostic test for identifying those patients likely to respond to IFN- $\alpha$.

\section{Acknowledgments}

We thank Dr. Francesco Dazzi for his critical appraisal during the preparation of the manuscript.

\section{References}

1. Gordon, M.Y., and J.M. Goldman. 1996. Cellular and molecular mechanisms in chronic myeloid leukaemia: biology and treatment. Br. J. Haematol. 95:10-20.

2. Amos, T.A.S., J.L. Lewis, F.H. Grand, R.P. Gooding, J.M. Goldman, and M.Y. Gordon. 1995. Apoptosis in chronic myeloid leukaemia: normal responses by progenitor cells to growth factor deprivation, $\mathrm{X}$-irradiation and glucocorticoids. Br. J. Haematol. 91:387-393.

3. Selleri, C., T. Sato, L. Del Vecchi, L. Luciano, A.J. Barrett, B. Rotoli, N.S. Young, and J.P. Maciejewski. 1997. Involvement of Fas-mediated apoptosis in the inhibitory effects of interferon-alpha in chronic myelogenous leukemia. Blood. 89:957-964.

4. Albrecht, T., R. Schwab, M. Henkes, C. Peschel, C. Huber, and W.E. Aulitzky. 1996. Primary proliferating immature myeloid cells from CML patients are not resistant to induction of apoptosis by DNA damage and growth factor withdrawal. Br. J. Haematol. 95:501-507.

5. Carlo-Stella, C., G. Dotti, L. Mangoni, E. Regazzi, D. Garau, A. Bonati, C. Almici, G. Sammarelli, B. Savoldo, M.T. Rizzo, et al. 1996. Selection of myeloid progenitors lacking BCR/ABL mRNA in chronic myelogenous leukemia patients after in vitro treatment with the tyrosine kinase inhibitor genistein. Blood. 88:3091-3100.

6. Roger, R., C. Issaad, M. Pallardy, M.C. Leglise, A.G. Turhan, J. Bertoglio, and J. Breard. 1996. BCR-ABL does not prevent apoptotic cell death induced by human natural killer cells or lymphokine-activated killer cells. Blood. 87:1113-1122.

7. Bedi, A., B.A. Zehnbauer, J.P. Baeber, S.J. Sharkis, and R.J. Jones. 1994. Inhibition of apoptosis by BCR-ABL in chronic myeloid leukemia. Blood. 83: 2038-2044.

8. Fernandez, R.S., A.M. Gorman, A. McGahon, M. Lawlor, S. McCann, and T.G. Cotter. 1996. The repression of apoptosis by activated abl oncogenes in chronic myelogenous leukaemia. Leukemia. 10(Suppl 2):17-21.

9. Talpaz, M., K. McCredie, H. Kantajian, J. Trujillo, M. Keating, and J. Gutterman. 1986. Chronic myelogenous leukaemia: haematological remissions with alpha interferon. Br. J. Haematol. 64:87-95.

10. Dowding, C., A.-P. Guo, D. Maisin, M.Y. Gordon, and J.M. Goldman 1991. The effects of interferon- $\alpha$ on the proliferation of CML progenitor cells in vitro are not related to the precise position of the M-BCR breakpoint. $B r . J$. Haematol. 77:165-171.

11. Galvani, D., and J.C. Cawley. 1989. Mechanism of action of $\alpha$ interferon in chronic granulocytic leukaemia: evidence for preferential inhibition of late progenitors. Br. J. Haematol. 73:475-479.

12. Olidapu-Williams, C., I. Svet-Moldavaskaya, J. Vilcek, T. Ohnuma, and J. Holland. 1981. Inhibitory effects of human leukocyte and fibroblast interferons on normal and chronic myelogenous leukemic granulocytic progenitor cells. Oncology. 338:356-360.

13. Gordon, M.Y., C.R. Dowding, G.P. Riley, J.M. Goldman, and M.F. Greaves. 1986. Altered adhesive interactions with marrow stroma of haematopoietic cells in chronic myeloid leukaemia. Nature. 328:342-344.

14. Gordon, M.Y., J. Atkinson, D. Clarke, C.R. Dowding, J.M. Goldman, P.G. Grimsley, M. Siczkowski, and M.F. Greaves. 1991. Deficiency of a phosphatidylinositol-anchored cell adhesion molecule influences haemopoietic progenitor binding to marrow stroma in chronic myeloid leukaemia. Leukemia. 5:693-698.

15. Verfaillie, C.M., J.B. McCarthy, and P.B. McGlave. 1992. Mechanisms underlying abnormal trafficking of malignant progenitors in chronic myelogenous leukemia. Decreased adhesion to stroma and fibronectin but increased adhesion to the basement membrane components laminin and collagen type IV.J. Clin. Invest. 90:1232-1241.

16. Dowding, C., A.-P. Guo, J. Osterholz, M. Sicskowski, J. Goldman, and M. Gordon. 1991. Interferon- $\alpha$ overrides the deficient adhesion of chronic myeloid leukemia primitive progenitor cells to bone marrow stromal cells. Blood 78:499-505.

17. Bhatia, R., E.A. Wayner, P.B. McGlave, and C.M. Verfaillie. 1994. Interferon-alpha restores normal adhesion of chronic myelogenous hematopoietic progenitors to bone marrow stroma by correcting impaired beta- 1 integrin receptor function. J. Clin. Invest. 94:384-391.

18. Gordon, M.Y. 1994. Plastic-adherent cells in human bone marrow generate long-term hematopoiesis in vitro. Leukemia. 8:865-870.

19. Gordon, M.Y., J.L. Lewis, F.H. Grand, S.B. Marley, and J.M. Goldman 1996. Phenotype and progeny of primitive adherent human hematopoietic progenitors. Leukemia. 10:1347-1351.

20. Grand, F.H., S.B. Marley, A. Chase, I. Titley, L. Healy, A. Spencer, A Reiter, J.M. Goldman, and M.Y. Gordon. 1997. BCR/ABL-negative progenitors are enriched in the adherent fraction of CD34+ cells circulating in the blood of chronic phase chronic myeloid leukemia patients. Leukemia. 11:14861492.

21. Gordon, M.Y., J.L. Lewis, S.B. Marley, F.H. Grand, and J.M. Goldman. 1997. Stromal cells negatively regulate primitive haemopoietic cell activation via a phosphatidylinositol-anchored cell adhesion/signalling mechanism. $B r . J$. Hematol. 96:647-653.

22. Wooldridge, M.J.A. 1995. A study of the incubation period, or age of onset, of the transmissible spongiform encephalopathies/prion diseases. Ph.D. thesis. University of London. 259 pp.

23. Altman, D. 1990. Practical Statistics for Medical Research. Blackwell Scientific Publications, Oxford, UK. 433 pp.

24. BMDP Statistical Software Manual. Vol 1. University of California Press, Berkeley, CA. 135 pp.

25. Udomsakdi, C., C.J. Eaves, B. Swolin, D.S. Reid, M.J. Barnett, and A.C. Eaves. 1992. Rapid decline of chronic myeloid leukemic cells in long-term culture due to defect at the leukemic stem cell level. Proc. Natl. Acad. Sci. USA. 89:6192-6196.

26. Marley, S.B., J.L. Lewis, M.A. Scott, J.M. Goldman, and M.Y. Gordon 1996. Evaluation of "discordant maturation" in chronic myeloid leukaemia using cultures of primitive progenitor cells and their production of clonogenic progeny. Br. J. Haematol. 95:299-305.

27. Talpaz, M., H. Kantarjian, K. McCredie, J. Trujillo, M. Keating, and J. Gutterman. 1986. Hematologic remission and cytogenetic improvement in duced by recombinant human interferon alpha $\mathrm{A}$ in chronic myelogenous leukemia. N. Engl. J. Med. 314:1065-1069.

28. Grunfeld, C., D.P. Kotler, J.K. Shigenaga, W. Dorrier, A. Tiernay, J. Wang, R.N. Pierson, and K.R. Feingold. 1991. Circulating interferon- $\alpha$ levels and hypertriglyceridemia in the acquired immunodeficiency syndrome. Am. J. Med. 90:154-162.

29. Bernier, J., A. Reuter, Y. Vrindts-Gevaert, and P. Franchimont. 1984 Radioimmunoassay of leukocyte (alpha) interferon and its application to some clinical conditions. J. Nucl. Med. 25:765-772.

30. Sherwin, S.A., J.A. Knost, S. Fein, P.G. Abrams, K.A. Foon, J.J. Ochs, C. Schoenberger, A.E. Maluish, and R.K. Oldham. 1982. A multiple-dose phase I trial of recombinant leukocyte A interferon in cancer patients. JAMA. 248: 2461-2466.

31. Corssmit, E.P.M., R. Heijligenberg, C.E. Hack, E. Endert, H.P. Sauerwein, and J.A. Romijn. 1997. Effects of interferon-alpha (IFN- $\alpha$ ) administration in healthy humans. Clin. Exp. Immunol. 107:359-363.

32. Eaves, C.J., and A.C. Eaves. 1997. Stem cell kinetics. Baillieres Clin. Haematol. 10:233-257. 